УДК 621.5 .048

\title{
Тривимірне моделювання нестаціонарного теплообміну під час охолодження води
}

\author{
Р. В. Грищенко, Я. І. Засядько, О. Ю. Пилипенко, А. В. Форсюк \\ Національний університет харчових технологій, вул. Володимирська, 68, м. Київ, 01601, Україна \\ e-mail: rgryshchenko@gmail.com
}

\begin{abstract}
Проведено дослідження і симулювання процесу нестаціонарного теплообміну під час охолодження води в дослідній секиії поблизу охолоджуваної вертикальної трубчастої поверхні. Побудовано та проведено аналіз графіків розподілу швидкості води по всій висоті досліджуваної секиії. Отримані результати дозволяють оиінити вплив температури води, щзо знаходиться поблизу точки інверсії $\left(+4^{\circ} \mathrm{C}\right)$, на динаміку танення та генерацію водного льоду, а також на конструктивні параметри акумуляторів холоду. Результати таких програмноаналітичних досліджень дадуть змогу по-новому підійти до проектування тепломасообмінного обладнання.
\end{abstract}

Ключові слова: тривимірне моделювання; граничні умови; теплообмін; акумулятори холоду; водний лід; танення водного льоду; ANSYS CFX

\section{Трехмерное моделирование нестационарного теплообмена при охлаждении воды}

\author{
Р. В. Грищенко, Я. И. Засядько, А. Ю. Пилипенко, А. В. Форсюк \\ Национальный университет пищевых технологий, ул. Владимирская, 68, г. Киев, 01601, Украина
}

\begin{abstract}
Проведено исследование и симуляциии процесса нестационарного теплообмена при охлаждении воды в исследовательской секции вблизи охлаждаемой вертикальной трубчатой поверхности. Построено и проведен анализ графиков распределения скорости воды по всей высоте исследуемой секиии. Полученнье результаты позволяют оценить влияние температуры воды, находящейся вблизи точки инверсии $\left(+4^{\circ} \mathrm{C}\right)$, на динамику таяния $и$ генерацию водного льда, а также на конструктивные параметры аккумуляторов холода. Результаты таких программно-аналитических исследований позволят по-новому подойти к проектированию тепломассообменного оборудования.
\end{abstract}

Ключевые слова: трехмерное моделирование; граничные условия; теплообмен; аккумуляторы холода; водный лед; таяние водного льда; ANSYS CFX

(C) The Author(s) 2017. This article is an open access publication

This work is licensed under the Creative Commons Attribution 4.0 International License (CC BY) http://creativecommons.org/licenses/by/4.0/

\section{1 Вступ}

Сучасний обчислювальний експеримент на етапі наукових досліджень, є одним із важливих при вирішенні лінійних і нелінійних, стаціонарних і нестаціонарних просторових задач різного роду. Інформація, отримана за допомогою чисельних розрахунків, дозволяє не тільки правильно осмислити і зрозуміти фізичні ефекти, що спостерігаються, наприклад, на експериментальних установках, а й у деяких випадках замінити реальний експеримент комп'ютеризованим. Іноді комп'ютерний експеримент $\epsilon$ єдиним можливим. Враховуючи подальший прогрес в області розвитку обчислювальної техніки, очікувано, що в найближчому майбутньому зросте роль комп'ютерного моделювання як у створенні нових зразків промисловості, так і в дослідженні процесів і явищ, що відбуваються в навколишньому світі. В даний час широке поширення одержали пакети обчислювальної гідродинаміки, тепломасообмі- ну, міцності та електродинаміки для проведення інженерних розрахунків.

\section{2 Постановка задачі}

Проблема, що розглядається, належить до надзвичайно складних комплексів проблем, взаємно пов'язаних та взаємно випливаючих завдань теплопередачі та гідродинаміки. При роботі з водою, що рухається повільно біля охолоджуваної поверхні, слід очікувати, що значна зміна густини води сильно вплине на розподіл швидкості в шарах близьких до охолоджуваної поверхні. Проблема ускладнюється коли температура води змінюється в межах $0 \ldots+10^{\circ} \mathrm{C}$, та має екстремальне значення при температурі $4^{\circ} \mathrm{C}$ (рисунок 1 ).

Очевидно, що аналітичний розрахунок гідродинаміки таких потоків неможливий, проте прогностичні розрахунки розподілу швидкості в зазначеній області надзвичайно корисні, оскільки локальна швидкість 
води визначає початок кристалізації на охолоджуваній поверхні (генерація льоду). Останнє є надзвичайно важливим на етапі проектування акумуляторів холоду. Слід також зазначити, що в літературі відсутні надійні розрахункові співвідношення для визначення коефіцієнта тепловіддачі при обтіканні вертикальної поверхні при спільному впливі природної та вимушеної конвекціï.

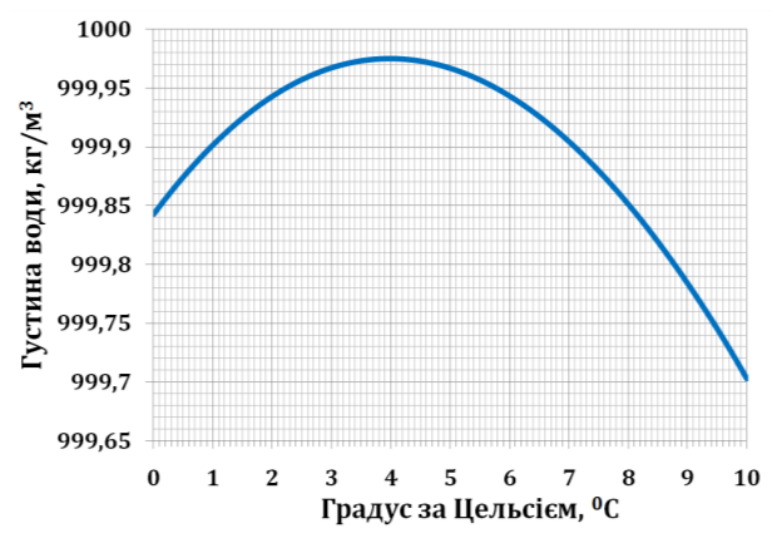

Рисунок 1 - Графік залежності густини води від темnератури

Застосування тривимірного комп'ютеризованого моделювання описаного вище процесу є надзвичайно перспективним на даний час, оскільки надає можливість 3'ясувати фізичну природу процесів, а також оцінити вплив гідродинаміки пристінної течії на початок льодоутворення.

\section{3 Експериментальна установка}

Дослідження динаміки плавлення і генерації водного льоду відбувається на експериментальному стенді, що зображений на рисунку 2.

Експериментальна установка являє собою циркуляційний по воді контур з дослідною секцією з охолоджуваною трубною поверхнею, на якій моделюються процеси генерації та плавлення водного льоду. Експериментальна секція виготовлена 3 органічного скла у формі труби внутрішнім діаметром 174 мм. По осі апарату встановлено мідну трубу діаметром 10 мм. Висота дослідної ділянки 300 мм.

Детальний опис дослідної установки розглянуто в роботах $[1,2]$.

\section{4 Створення тривимірної моделі}

Геометрична модель дослідної ділянки побудована в пакеті програм Ansys. Ядро геометричної моделі є областю коаксіального циліндра, в середині якого протікає вода. Чотири впускних та випускних патрубків для води знаходяться на нижній та верхній частині циліндра. Охолоджувана циліндрична поверхня моделюється вздовж центральної осі (рисунок 3 ).

Для того, щоб забезпечити найбільш досяжну точність розрахунку при розумному числу ітерацій, дослідна секція згенерована як сектор 90 градусів. Особливу увагу було приділено належному рівню створення сітки. Це дало можливість генерувати 500000 вузлів сітки в межах сектора, що дорівнює 2 млн. вузлам, для розрахунку цілого циліндра. Для більш точних розрахунків, а також щоб сформувати сітку прикордонного шару, використано спеціальну межу інфляції (рисунок 4).

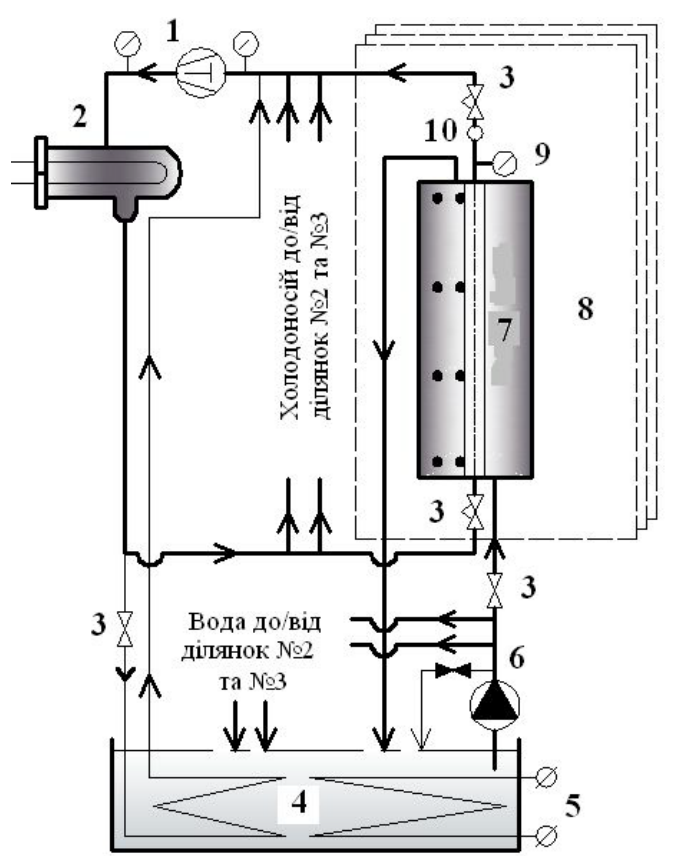

1 - компресор, 2 - кожухотрубний конденсатор, 3 - регулюючий вентиль, 4- ємність з водою, 5 - ТЕН, 6- насос, 7 - дослідна труба, 8 - дослідна секиія,

9 -манометр, 10 - оглядове віконце.

Рисунок 2 - Принципова схема дослідної установки

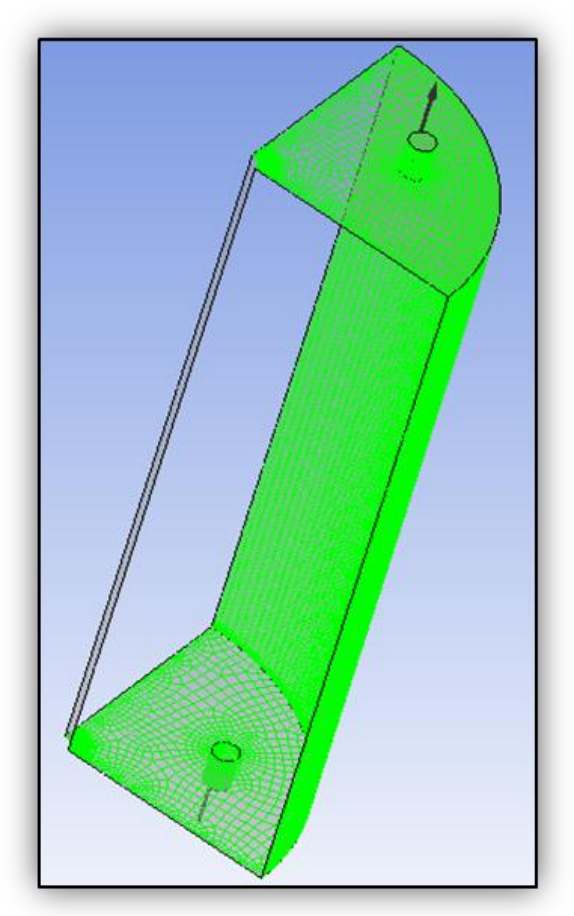

Рисунок 3 - Геометрична модель дослідної секції 
При проведенні нестаціонарного розрахунку створено декілька геометричних моделей дослідної секції 3 різними діаметрами охолоджуваної поверхні (симулювання генерації льоду). Таке рішення було прийнято для спрощення самої тривимірної моделі. Температура внутрішнього циліндра запрограмована як поверхня 3 температурою $0^{\circ} \mathrm{C}$, щоб уникнути можливого обмерзання на поверхні охолоджуваної стінки. Температура води, коливалася в межах інтервалу від +10 до $+40{ }^{\circ} \mathrm{C}$. Модель турбулентності обрано SST (Shear-StressTransport), оскільки дана модель ефективно поєднує стійкість і точність стандартної k-w моделі в пристінних областях та k-е моделі в ядрі потоку.

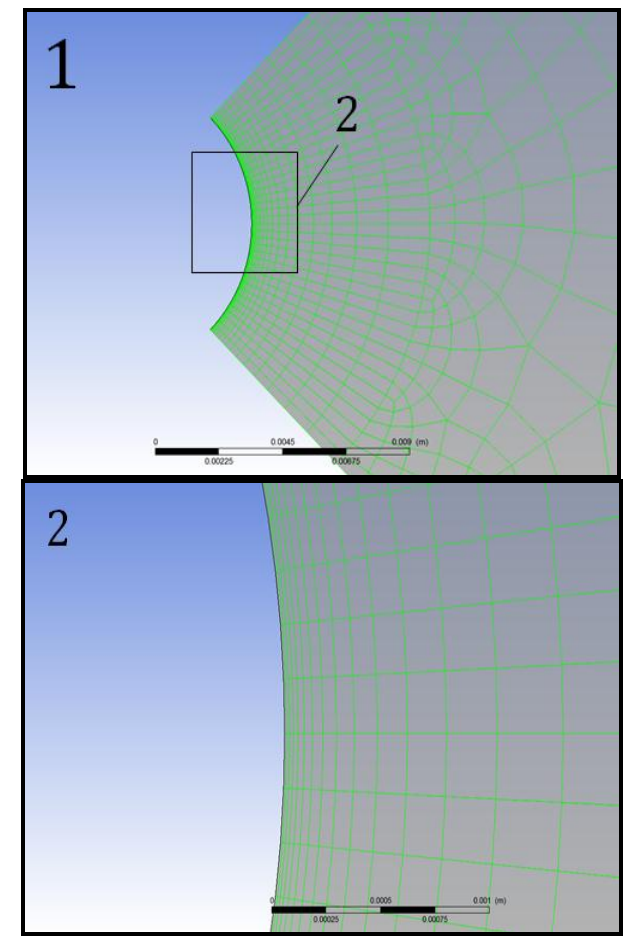

Рисунок 4 - Межа інфляції в граничному прошарку (охолоджувана стінка - теплоносій)

Для належного розрахунку поставленої задачі в програмний модуль введено фізичні параметри охолоджуваної води, а саме густина води та теплоємність 3 кроком в один градус Цельсія в межах дослідного інтервалу температур (рисунок 5).

Розрахунки проводились в менеджері CFX - Solver. Точність отриманих результатів демонструється сходженням розрахованої системи рівнянь та складає понад 1520 ітерацій. Результати попередніх програмноаналітичних досліджень [1] використано під час нестаціонарного розрахунку тривимірної моделі. Розрахунок проводився в декілька етапів, в кожен 3 яких заряджалась нова розрахункова сітка зі зміненим зовнішнім діаметром охолоджуваної поверхні (рисунок 6). При запрограмованому часі симуляції 600 секунд діаметр охолоджуваної поверхні змінювався від 5 до 8 мм, що в реальному часі дорівнює приблизно товщині згенерованого водного льоду на охолоджуваній поверхні. Даний підхід дозволив уникнути складних програмних розрахунків, що вимагають серйозних ресурсних затрат.
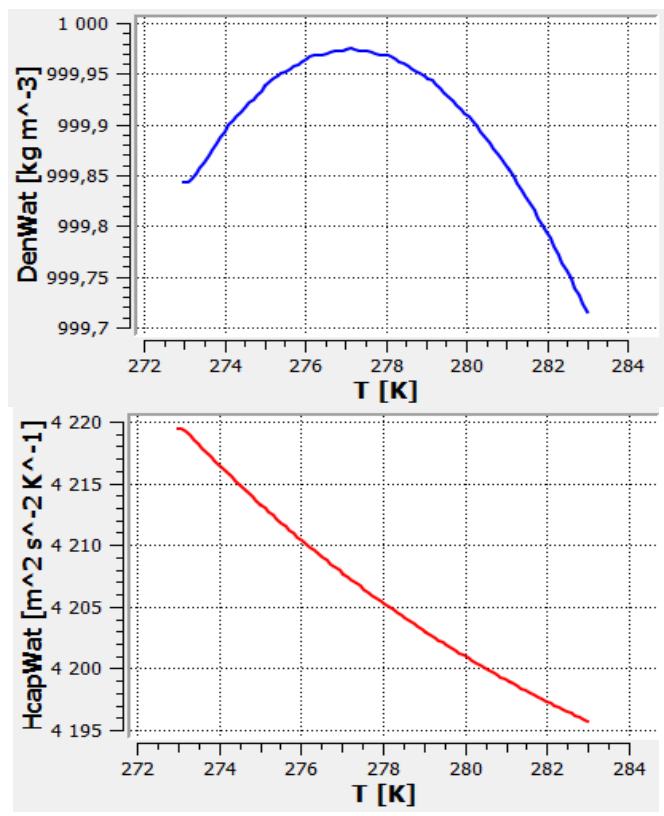

Рисунок 5 - Густина та теплоємність води, відповідно, запрограмована в розрахунковий модуль.

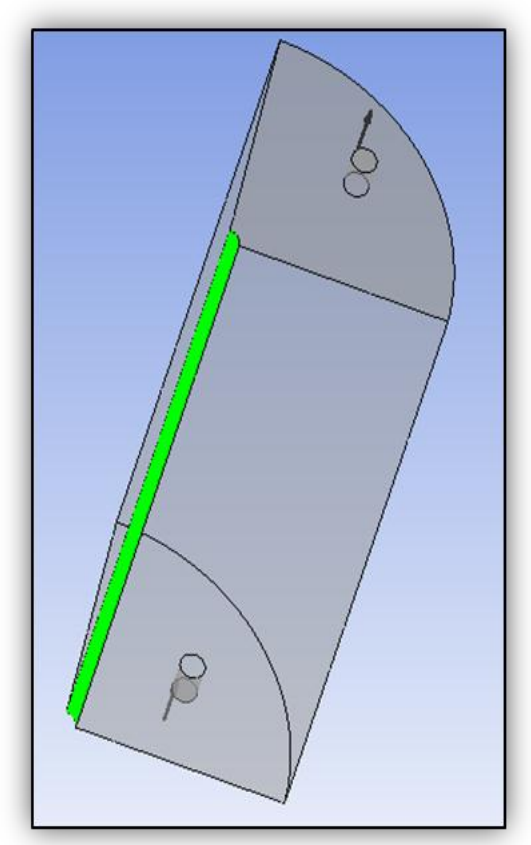

Рисунок 6 - Геометрична модель в якій змінювався діаметр охолоджуваної поверхні

Отримані результати імпортовано до CFD-Post. Представлені профілі температури рідини через певні проміжки часу (рисунки 7, 8). Представлені результати дають можливість оцінити вплив режимних параметрів на процес охолодження води. Так при перегляді профілю розподілу температури по всій поверхні колби спостерігається найбільш інтенсивне переохолодження води саме в нижній частині дослідної секції.

Це пояснюється аномальним перерозподілом густини води, тобто шари рідини, що знаходяться поблизу мідної поверхні, охолоджуються нижче $4{ }^{\circ} \mathrm{C}$, при яких густина води зменшується, починають перемішуватися 
3 шарами, які мають температуру в $4{ }^{\circ} \mathrm{C}$, що призводить до локального перемішування шарів води саме в граничному прошарку (мідна стінка - теплоносій). Також спостерігається падіння швидкості води до ії мінімального значення в дослідній секції по висоті 6 мм. Дані результати дослідження підтверджено натурним експериментом. Отримані результати співпадають 3 попередніми розрахунками, що представлені в роботі [1].
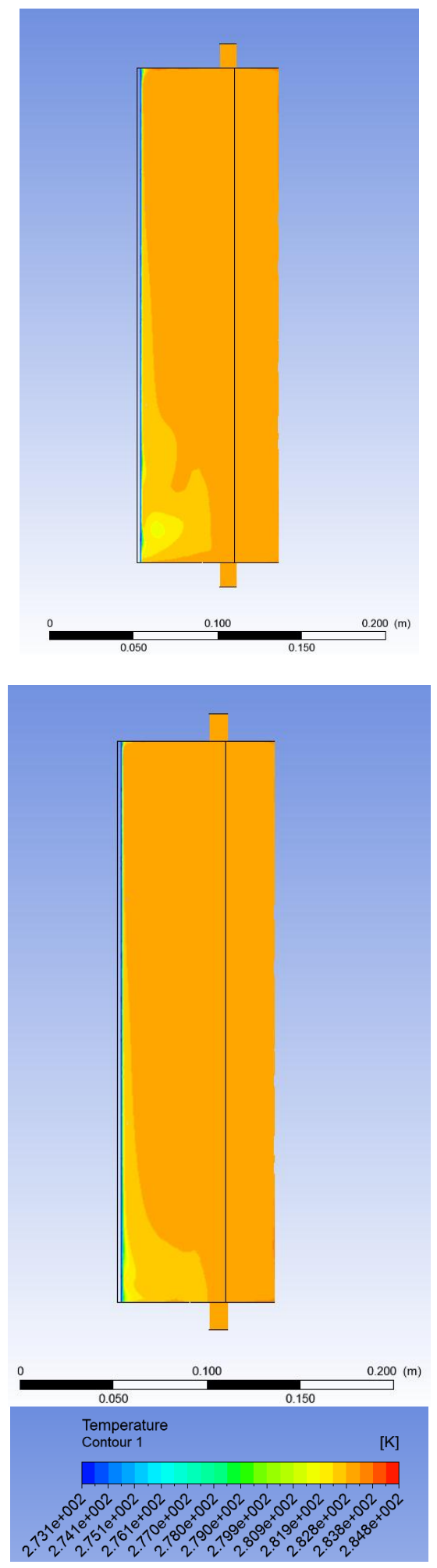

Рисунок 7 - Профіль температури води в інтервалі 200 c.

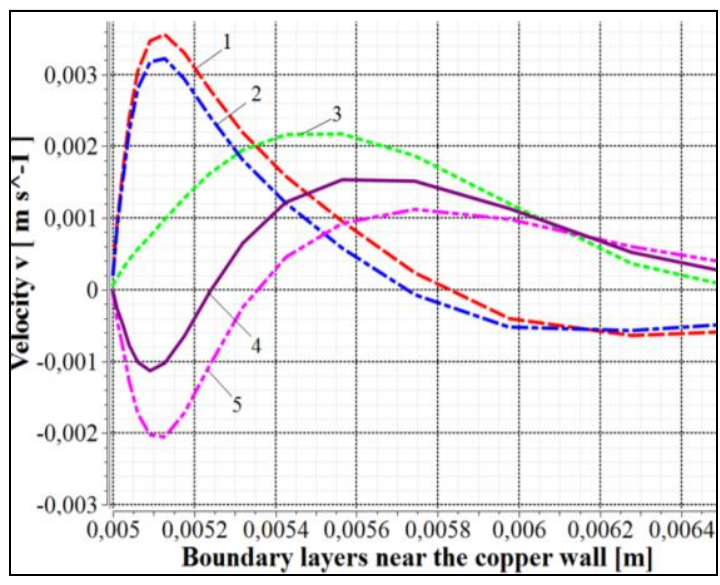

1,2,3,4,5 - Швидкість по висоті дослідної секиї 0,1 м; 0,15 м; 0,06м;0,058м;0,059м; відповідно.

Рисунок 8 - Графік розподілу швидкості води по всій висоті дослідної секиії в межах граничного прошарку

\section{5 Висновки}

Результати тривимірного моделювання нестаціонарного охолодження і руху води дозволяють оцінити вплив температури води, що знаходиться поблизу точки інверсії, на динаміку плавлення та генерацію водного льоду.

Отримані результати програмно-аналітичного дослідження охолодження води дають зрозуміти, що екстремальний характер густини води змінюється впритул до точки інверсії та значно впливає на розподіл швидкості в прикордонному шарі.

Дані результати вказують, що початок кристалізації водного льоду починається 3 нульового поперечного перерізу профілю швидкості. Це підтверджено результатами фотофіксації реального експерименту [1].

\section{Література}

1. 3D modeling of water flow and cooling down within the temperature range close to inversion point / Roman Gryshchenko, Yaroslav Zasiadko, Oleksiy Pylypenko, Andriy Forsiuk // Journal of Faculty of Food Engineering, Ştefan cel Mare University of Suceava, Romania Volume XV, Issue 4, 2016, pp. 323-328

2. Пилипенко, О. Ю. Динаміка кристалізації льоду на вертикальних охолоджуваних трубах в елементах акумуляторів теплової енергії систем охолодження та кондиціювання повітря [Текст]: дисертація ... кандидата технічних наук / О. Ю. Пилипенко - Київ, 2012. - 267 с.

\footnotetext{
Отримана в редакції 09.10.2017, прийнята до друку 08.12.2017
} 


\section{Three-Dimensional Modeling of Non-Stationary Heat Exchanger with Water Cooling}

R. Gryshchenko, Ya. Zasiadko, O. Pylypenko, A. Forsiuk

Nathional University of Food Technologies, 68 Volodymyrska str., Kyiv, 01601, Ukraine

The research and simulation of the process of non-stationary heat exchange, during cooling of water in the experimental section, near the cooled vertical cylindrical surface is carried out. The analysis of graphs of water velocity distribution along the entire height of the studied section was constructed and carried out. The obtained results allow us to estimate the influence of water temperature near the inversion point $\left(+4^{\circ} \mathrm{C}\right)$, on the melting dynamics and generation of water ice, as well as on the design parameters of cold accumulators. The results of such programmatic and analytical studies will allow a new approach to the design of heat and mass equipment.

Keywords: computer modeling, boundary conditions, heat transfer, cold accumulators, water ice, ice melting, ANSYS $C F X$.

\section{References}

1. Roman Gryshchenko, Yaroslav Zasiadko, Oleksiy Pylypenko, Andriy Forsiuk (2016) 3D modeling of water flow and cooling down within the temperature range close to inversion point. Journal of Faculty of Food Engineering, Ştefan cel Mare University of Suceava, Romania, 15(4), 323-328.
2. Pylypenko, O. Iu. (2012) Dynamika krystalizatsii lodu na vertykalnykh okholodzhuvanykh trubakh $\mathrm{v}$ elementakh akumuliatoriv teplovoi enerhii system okholodzhennia ta kondytsionuvannia povitria: dysertatsiia ... kandydata tekhnichnykh nauk, Kyiv, 267 p.

Received 09 October 2017 Approved 08 December 2017 Available in Internet 23 December 2017 